\title{
Engaging Technology
}

David J. Rosen, Newsome Associates

Each Technology Solutions for Adult Basic Skills Challenges column begins with a common challenge facing adult basic skills practitioners. Solutions offered for these challenges, at least in part through the use of technology, include hardware or software applications such as websites, course management systems, learning management systems, and apps for mobile devices. Each article begins with a description of a teaching challenge, and then examines solutions that involve the use of technology.

\section{Description of the Challenge}

When this column was written, most or all adult basic skills education as well as K-12 and higher education were being delivered remotely; many teachers who were new to remote or online teaching were faced with how to keep students engaged. Online courses have a reputation, sometimes but not always deserved, for being tedious, boring, or irrelevant to the challenges of adult learners' daily lives. Because so much of what else happens online is designed to be engaging or entertaining, such as movies, online gaming, social media, and instant messaging, online teachers have an especially difficult challenge to engage learners.

Some might argue that when students have difficulty getting online and maintaining the access and bandwidth needed for online learning, the technology itself is a reason that some learners do not get engaged. They also point out that the digital divide in the United States, which has received new attention as a result of the pandemic, may be exacerbated for low-income families because of the loss of their jobs that are needed to pay for internet hardware and access from home.

Nevertheless, some teachers and adult learners have managed to overcome these challenges and to have engaging online teaching and learning. In this Technology Solutions column, we will look at what technology they use, and what they do with it. If you are reading this when in-person learning is again possible, you may still find this column useful if you are thinking about what in the online part of your blended learning approach could engage your students.

\section{Possible Solutions}

\section{Find online equivalents to what engages students in your in-person classes.}

Many adult basic skills educators, especially those who teach English language learners online, have found the free app called WhatsApp useful and engaging. Nearly all ESOL/ESL learners now have a smartphone and many of them use WhatsApp for communicating with family and friends in the United States and in their countries of origin. Although using WhatsApp for learning purposes is new to them, the app 
itself is familiar and comfortable. There have been several good discussions in the LINCS English Language Acquisition and Integrating Technology groups about using WhatsApp. To find them, go to https://community.lincs. ed.gov/ and, using the Search feature, type in "WhatsApp." Especially pertinent to learner engagement is an effort in the LINCS English Language Acquisition group by five very experienced adult ESOL/ESL teachers and teacher educators from across the country to identify ways that WhatsApp could approximate what teachers have successfully done in in-person classes. https://community. lincs.ed.gov/group/20/discussion/whatsapponline-equivalents-person-teaching-practices

\section{Find software, including apps, that are designed to engage students in an online learning environment.}

Flipgrid (free) is a video discussion platform that enables learners to share short, easilymade videos on a computer or smartphone in response to their teachers' specific assignment videos that have also been made using Flipgrid. Here are some examples: adult learners who are new to an online class could easily introduce themselves, and their families if they wish, in a relaxed way, in videos that range from 30 to 60 seconds. If you teach numeracy or math, you could ask students who have found a solution to a math problem to explain their thinking, in a 2-minute video shared with the class. If you teach immigrants learning English, you could ask them to make a short video - in English - in which they roleplay introducing themselves to a new neighbor, to someone new at work, or to the parent of one of their children's new friends. You could give them a framework of sentence starters to complete, such as: "Hello, my name is looking forward to ___." "If you teach reading, you could assign students stories or articles to read and then do a video review. You could provide points for them to address in their two- or three-minute review such as the title, author, theme(s), main idea(s), summary of the characters and plot, or what they especially liked or did not like about the story or article. If you teach high school equivalence exam preparation you could ask students to respond to questions about a critical current event as idea starters for an essay about the event. If you teach writing, you could ask students to review a book, movie, or television show in writing, and then summarize it in a succinct, one-minute Flipgrid video.

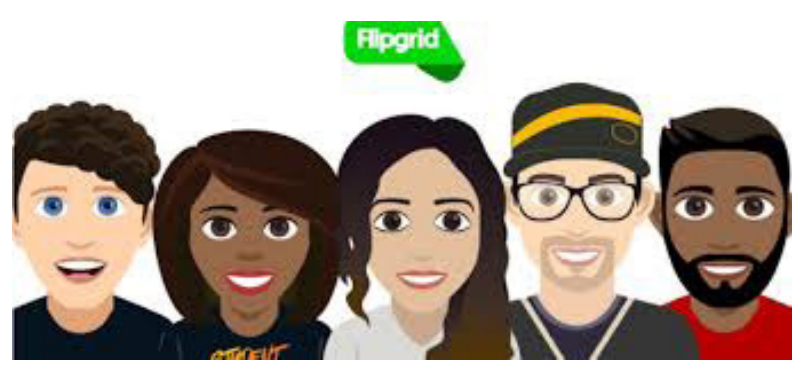

Created in 2012 by Dr. Charlie Miller, a professor of design at the University of Minnesota, to use with his doctoral students, Flipgrid has been used by millions of educators and learners from PreK to PhD. It's a website in which teachers/instructors create "grids" as prompts for video discussions. In each grid, a teacher can ask a question, called a "topic" and their students can post video responses that appear in a tiled grid display.

The name "Flipgrid" may refer to a "flipped classroom" model in which a teacher assigns a homework question for students to respond to with a short video. Then, in class, the students 
watch and discuss their video responses. Flipgrid offers a collection called the Disco Library that has a wide range of topic videos shared by teachers around the world. A Flipgrid blog and Twitter feed also offer lots of helpful tips and ideas for using Flipgrid with students. Some teachers have found that Flipgrid helps students to practice and build their social skills and connect with one another, fostering an online and/or in-person learning community. Flipgrid can be accessed free through its website, and is available for download at the iOS App Store and the Google Play Store.

- How to get started with Flipgrid: http:// blog.flipgrid.com/news/highered

- Ideas for using Flipgrid: https://blog. flipgrid.com/news/category/Ideas Check out the 11 "Tips for the Camera Shy" October 2, 2019.

PowToon is a cartoon video maker that has a free trial version and, from my experience, is easy to learn. With it, teachers can make short, engaging, animated videos that learners often say they like.

- English language professor Helaine Marshall, for example, has developed this engaging PowToon video to introduce her graduate students to English grammar.

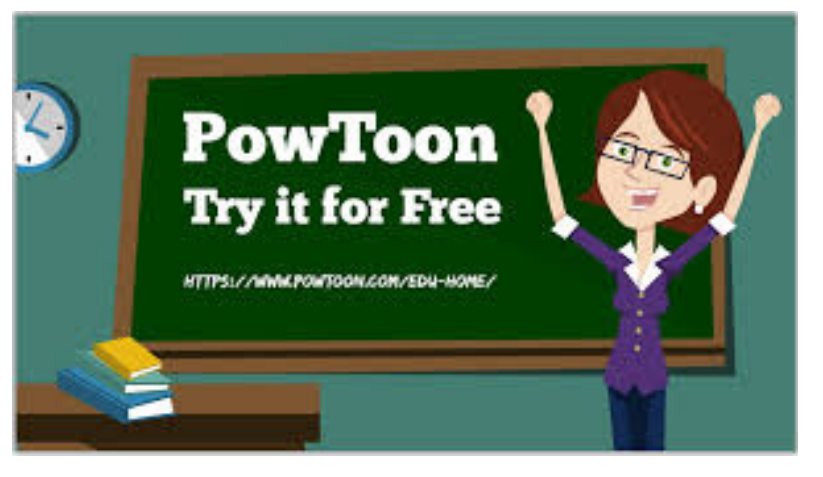

Adult Literacy XPRIZE Finalist Apps. As you may know, the Adult Literacy XPRIZE was a multi-year international competition in which teams of software developers created apps for basic level adult English language learners and so-called "zero to three" level native speakers of English who wanted to acquire or improve reading and writing skills. To find descriptions of the finalists visit https://bit.ly/3lUQXQj. Some of these apps use game strategies, short entertaining videos, music and personal engagement strategies. Some users of at least one, Learning Upgrade, are so engaged that they "binge learn" late at night, after their children are in bed, when they have time for themselves. Instead of playing games on their smartphone, they do hours of engaging Learning Upgrade lessons.

\section{Use the capabilities of particular electronic} or digital tools that enhance personalization, relationship-building, encouragement, and confidence-building.

Here is a short list of mostly familiar online communication tools that adult basic skills teachers have used to personalize their teachinglearning relationships with their students:

- Telephone and telephone conferencing

- Email

- Instant messaging

- One-on-one screen sharing software such as join.me

- Nudge software to remind students of their goals, objectives, commitments, scheduled meetings, etc. One example of nudge software is SignalVine

- Free workgroup software such as Google Groups or Slack. 
4. Re-design your instruction for a "new normal" in which you offer both online and in-person engaging choices for all your teaching that together meet the full range of students' learning needs under normal and emergency circumstances.

Some adult learners want only in-person, realtime classes; some want only remote classes or asynchronous instruction; some want both; some start out with in-person but then want to (or must) shift to remote learning; some may start out online but miss real-time, in-person interaction; some, who prefer classes in-person but cannot attend them all, can mix modes. This way of blending learning, in which each mode includes a complete curriculum of lessons that address the same content standards, has come to be called "blendflex" or "hyflex" teaching and learning. For many adult learners it can mean not having to drop out of a class but, instead, to shift their mode of learning. This can also be a benefit to programs, increasing student retention, so this design may have appeal to both adult basic skills program administrators and adult learners. Its design, however, is complex, and its management, by a teacher, may be more than some teachers can or wish to do. The model can be built a step at a time, however, with the goal of a fully implemented project in several years. Visit https://bit.ly/3hXkslp for more information about these higher education Blendflex and HyFlex models.

\section{Reflections}

Technology may offer a broader range of solutions for designing engaging classes or tutorials, but it cannot, by itself, address learners' needs. With or without the help of technology, teachers' must ask about and listen to adult students' perceptions of their needs, and do this with each new group of students so that over time their program has a good sense of the range of students' needs, and of the patterns of widely-held needs such as scheduling flexibility, that may be stable from year to year. Engaging and effective teaching -- classes, tutorials, curricula or programs - whether inperson or online, is built from an understanding of students' needs and goals, and from knowledge about what is effective in addressing them.

There is much more to engagement than using technology, of course. Teaching styles play an important part, as does the opportunity for learners to actively engage in their learning, for example through learning projects, role playing, or other kinds of active, participatory learning. As should always be the case in a teaching and learning context, technology is a set of tools, in this case digital tools, in service of education goals and objectives, and of learners. 